\title{
Hilirisasi Industri Kopi Berorientasi Pasar Cafe kepada Masyarakat Petani Kopi di Dusun Tuo Limbur Kabupaten Bungo
}

\author{
Ikhsan Alfarisi ${ }^{a, 1, *}$, Joko Susanto ${ }^{\text {b,2 }}$, H.M. Chotib ${ }^{\text {b,3 }}$, Fajar Ifan Dolly ${ }^{b, 4}$, Yasmir ${ }^{b, 5}$, Deni \\ Handani ${ }^{\mathrm{b}, 6}$ \\ ${ }^{\mathrm{a}, \mathrm{b}}$ STIA Setih Setio Muara Bungo, Jambi \\ ${ }^{1}$ Ikhsanalfarisi19@gmail.com *; ${ }^{2}$ jokosusantoo251@ gmail.com; ${ }^{3}$ hm.chotib@gmail.com; ${ }^{4}$ \\ Fajarifandolly53@gmail.com; ${ }^{5}$ Yasmir.ok1981@ gmail.com; ${ }^{6}$ Denihandani91@ gmail.com \\ * corresponding author
}

\section{ARTICLE INFO}

Article History

Received,11-11-2020

Revised,16-01-2021

Accepted,20-01-2021

\section{Keywords}

Downstreaming;

Coffee Industry;

Coffee Farmers.

\begin{abstract}
The coffee industry in Indonesia can be said to be stretching, coffee has now become a lifestyle. The mushrooming of coffee shops in various regions in Indonesia is a sign of this. The skyrocketing coffee industry is inseparable from the development of the world coffee industry, which until now the quality coffee commodity has become the target of both national and international coffee entrepreneurs, including in the city of Muara Bungo. The problem of the coffee industry in Bungo district in general is the difficulty in finding local coffee raw materials, so that opportunities for local coffee farmers who are in accordance with the demands of business actors in the coffee sector to increase the selling value of coffee are wide open. This article describing the problems of coffee processing for the quality of coffee beans from the farmers to entering the coffee industries in the city of Muara Bungo. To achieve this goal, it is necessary to carry out counseling / training on coffee cultivation and coffee processing practices in accordance with the standards of market demand for cafes in the city of Muara Bungo. The enthusiasm of the participants in participating in this training was very impressive, this could be seen from the questions submitted by the training participants regarding good and quality oriented coffee cultivation, the participants got new insights and experiences, including knowing coffee bean processing techniques in accordance with cafe market demand in Muara Bungo city, the distribution channel to the cafe market as well as the desired coffee processing and serving practices of the cafe market as well as through this activity bridging coffee beans from farmers to coffee roasters in the city of Muara Bungo. Some of coffee beans from the farmers in Tuo Limbur was distributed to coffee roasters in the city of Muara Bungo.
\end{abstract}

\section{PENDAHULUAN}

Pertumbuhan ekonomi nasional saat ini menunjukkan tren meningkat dalam skala ekonomi makro, tetapi sektor makro juga harus diimbangi dengan pertumbuhan signifikan dari sektor ekonomi mikro dalam upaya penguatan perekonomian nasional. Di beberapa negara kawasan asia tenggara, kebijakan penguatan sektor ekonomi mikro telah dilakukan sejak beberapa tahun yang lalu dengan memberikan pinjaman lunak (soft loan) kepada masyarakat yang memiliki konsep usaha mikro, kecil dan menengah (UMKM).

Kebijakan pemerintah Indonesia dalam beberapa tahun terakhir juga mengarah kepada penguatan sektor ekonomi mikro yang ditandai dengan program perbankan nasional berbentuk Kredit Usaha Rakyat (KUR) dan pemerintah saat ini-pun membentuk Badan Ekonomi Kreatif untuk menstimulasi ekonomi kreatif di Indonesia. Industri kopi dilirik pemerintah sebagai target pengembangan industri kreatif dengan menggandeng penggiat kopi untuk hadir di Istana negara di akhir tahun 2017 ini berbincang dengan presiden terkait industi kopi mulai dari hulu ke hilir. (Nasional, Kompas.com, 2017)

Indonesia adalah produsen kopi ketiga setelah Brazil dan Kolombia dengan hasil produksi nasional berkisar 650-700 ton per tahun dengan jumlah ekspor sebesar 450 tonper tahun dengan 
total nilai ekspor sebesar USD1,2 miliar atau sekitar Rp16,8 triliun.Negara-negara tujuan ekspor utama kopi Indonesia antara lain Amerika Serikat sebesar 67ton, Jerman 42ton, Malaysia 39ton, Italia 36 ton dan Jepang 35ton. (economy.okezone.com, 2018)

Industri kopi di Indonesia dapat dikatakan sedang menggeliat, kopi saat ini sudah menjadi sebuah tren dan gaya hidup. Menjamurnya coffee shop di berbagai daerah di Indonesia menjadi indikator hal tersebut. Meroketnya industri kopi tidak terlepas dari perkembangan industri kopi dunia yang hingga saat ini komoditas kopi berkualitas menjadi incaran dari pelaku usaha kopi baik nasional maupun internasional.

Permasalahan industri kopi di kabupaten Bungo secara umum adalah kesulitan dalam mencari bahan baku kopi lokal dan ketidaktersediaan alat pengolahan biji kopi yang memenuhi standar permintaan biji/bubuk kopi kelas cafe yang membutuhkan teknologi modern.

Pasokan Kopi kelas cafe yang ada di kota Muara Bungo didapatkan oleh pelaku usaha di bidang kopi dari luar daerah seperti Jakarta, Makassar, Bandung dan yang terdekat dari Solok, Sumatera Barat atau dari Kerinci, Jambi. Petani kopi yang ada di Kabupaten Bungo terutama di daerah DusunTuo Limbur yang menjadi lokasi pengabdian belum mengolah biji kopi menjadi bahan yang siap pakai untuk industri kopi di kota Muara Bungo.

Tingginya permintaan kopi kelas cafe di kota Muara Bungo berbanding lurus dengan menggeliatnya bisnis kopi di kota Muara Bungo yang menjadi peluang bagi petani lokal untuk mendapatkan nilai tambah daripada harus menjual mentah biji kopi kepada tengkulak dengan harga murah untuk dibuang ke Provinsi lain seperti Sumatera Barat dan Ibukota Provinsi, Jambi. Hal ini didukung dengan lesunya perekonomian di Kabupaten Bungo karena melemahnya harga komoditas perkebunan utama yaitu karet dalam beberapa tahun terakhir yang menjadi sumber pendapatan utama bagi masyarakat Kabupaten Bungo.

Oleh karena hal tersebut, pengabdian masyarakat oleh tim dosen STIA Setih Setio Muara Bungo ini dipandang perlu kiranya untuk memfasilitasi jalur distribusi dan memberi pelatihan kepada masyarakat petani kopi dalam meningkatkan nilai jual biji kopi yang ada di Dusun Tuo Limbur dari mulai proses pemilihan bibit, penanaman, perawatan, panen, sortasi biji dan pengolahan pasca panen.

Pelatihan dan penyuluhan ini bertujuan untuk memberi tambahan wawasan peserta dalam seluruh rangkaian proses hulu ke hilir industri kopi yang bisa diterima pasar cafe yang ada di Kota Muara Bungo dan sekaligus menjembatani petani ke pelaku usaha industri kopi yang ada di Kota Muara Bungo khususnya pelaku usaha kopi dalam bidang micro roastery. Dalam jangka panjang petani dapat memproduksi, mengemas dan menjual kopi berkualitas.

\section{PELAKSANAAN DAN METODE}

Persiapan kegiatan dilaksanakan selama satu bulan sebelum penyuluhan. Pelaksanaan kegiatan pengabdian kepada masyarakat ini dilaksanakan pada Bulan Agustus 2019 di Dusun Tuo Limbur Kabupaten Bungo. Proses persiapan meliputi riset di dusun Tuo Limbur Kabupaten Bungo tentang potensi kopi yang dimiliki petani dan kondisi geografis dusun Tuo Limbur. Data diambil dari observasi lapangan, wawancara dengan warga dusun Tuo Limbur Kabupaten Bungo tentang proses hulu ke hilir budidaya kopi yang ada di dusun Tuo Limbur sebelum penyuluhan. Data dilapangan dijadikan bahan untuk merencanakan kegiatan yang akan dilakukan yang akhirnya diputuskan untuk melakukan sosialisasi dengan metode ceramah melalui media slide presentasi dan proyektor, sesi Focus Group Discussion dengan petani kopi melalui tanya-jawab, dan demonstrasi penyajian kopi yang ada di pasar cafe Muara Bungo dengan alat-alat manual brewing yang terdiri dari biji kopi yang sudah roasting, grinder, vietnam drip dan mesin espresso manual rok presso.

Koordinator pelaksana dan anggota bekerjasama dalam kegiatan yang meliputi perencanaan, pelaksanaan danpelaporansaat akhir kegiatan. Tiap pelaksana memiliki tanggung-jawabnya masing-masing. Koordinator pelaksana bertanggung jawab penuh terhadap segala urusan kegiatan yang meliputi perencanaan, pelaksanaan, dan pelaporan. Penanggung-jawab keuangan bertanggung-jawab pada tugas mengatur pengeluaran keuangan. Hubungan masyarakat dan publikasi bertugas menyusun laporan pengabdian. 


\section{HASIL DAN PEMBAHASAN}

Kegiatan pengabdian yang dilakukan di Dusun Tuo Limbur, Kecamatan Limbur Lubuk Mengkuang. Kegiatan sosialisasi inidilaksanakan dengan metode ceramah melalui presentasi keseluruhan materi dan pelatihan/praktik penyajian kopi dengan metode manual brewingserta Focus Group Discussion. Secara garis besar ada beberapa materi pokok dalam sosialisasi ini, antara lain;

- Bahan tanam anjuran dan teknik perbanyakan tanaman kopi (pembibitan);

- Syarat tumbuh kopi, persiapan lahan dan penanaman kopi;

- Konservasi lahan dan pemupukan kopi;

- Pangkasan kopi dan pengelolaan penaung;

- Diversifikasi tanaman kopi dengan tanaman lain dan ternak;

- Pengelolaan Organisme Penggangu Tanaman (OPT) kopi;

- Panen dan pasca panen kopi;

- Industri hilir kopi.

Kegiatan pertama diawali dengan penyuluhan kepada masyarakat petani kopi di Dusun Tuo Limbur tentang budidaya, pengolahan biji kopi dan industir hilir kopi serta ditutup dengan praktik penyajian kopi yang disesuaikan dengan pasar cafe di Kota Muara Bungo.

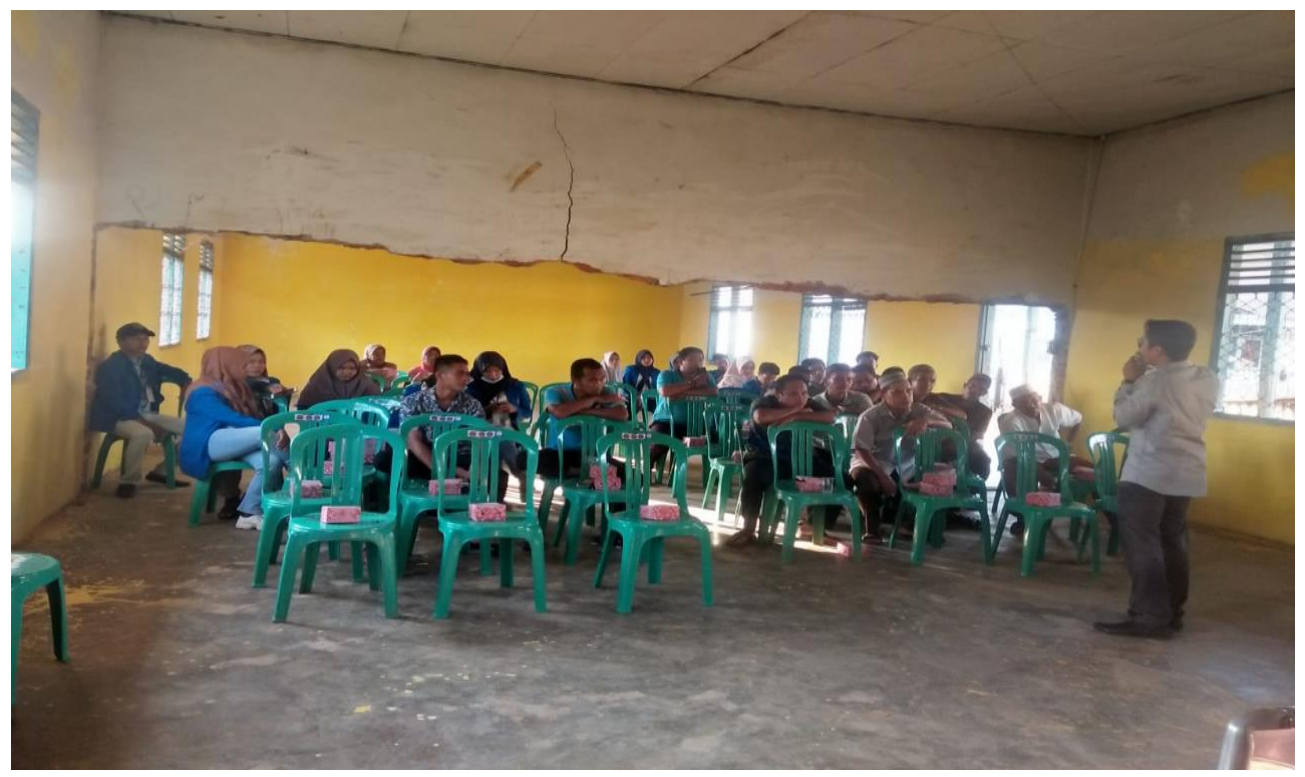

Gambar 1. Sosialisasi Hilirisasi Industri Kopi

Sosialisasi pertama kali dilakukan dengan metode ceramah dari paparan narasumber Ikhsan Alfarisi, S.H., M.H dengan dimoderatorioleh Fajar Ifan Dolly, S.Sos., M.Si kepada masyarakat petani kopi tentang budidaya kopi mulai dari pemilihan bibit, penanaman dan perawatan pohon kopi, kemudian dilanjutkan dengan sosialisasi pengolahan biji kopi dan pengenalan kepada mesin pengolahan biji kopi seperti mesin pengupas dan pengering. Kemudian dilanjutkan dengan membedah metode pengolahan kopi dengan metode basah(Semi Wash dan Full Wash) dan kering (Honey Process dan Natural Process) selanjutnya dilanjutkan dengan tanya jawab mengenai keseluruhan topik yang dibahas saat sosialisasi.

Antusiasme petani kopi dalam mengikuti sosialisasi ini terlihat dari berbagai pertanyaan yang menyangkut budidaya kopi antara lain dimana mendapatkan bibit terbaik dari tanaman kopi? jenis atau varietas tanaman kopi apa yag cocok untuk kondisi geografis Dusun Tuo Limbur? Perlukah tanaman peneduh? Berkaitan dengan perawatan tanaman kopipertanyaan mengenai bagaimana mengatasi serangan hama yang menyebabkan karat daun dan pohon kopi menjadi mati? Haruskah membersihkan areal sekitar tanaman kopi dan melakukan pemangkasan? Dalam pengolahan, perlukah melakukan sortasi? Berapa lama waktu perendaman jika menggunakan metode pengolahan basah/full wash? Berapa lama waktu pengeringan biji kopi cherry? Bisakah menggunakan huller padi dalam pengupasan kulit tanduk biji kopi cherry? Dalam pengolahan 
lanjutan dijelaskan mengenai proses pengolahan kopi saat roasting dan grinding di micro roastery dan pengemasan, sehingga para petani memahami kebutuhan pasar cafe dan di kemudian hari dapat mengolah sendiri sampai ke tahap pengemasan dan pemasaran secara mandiri.

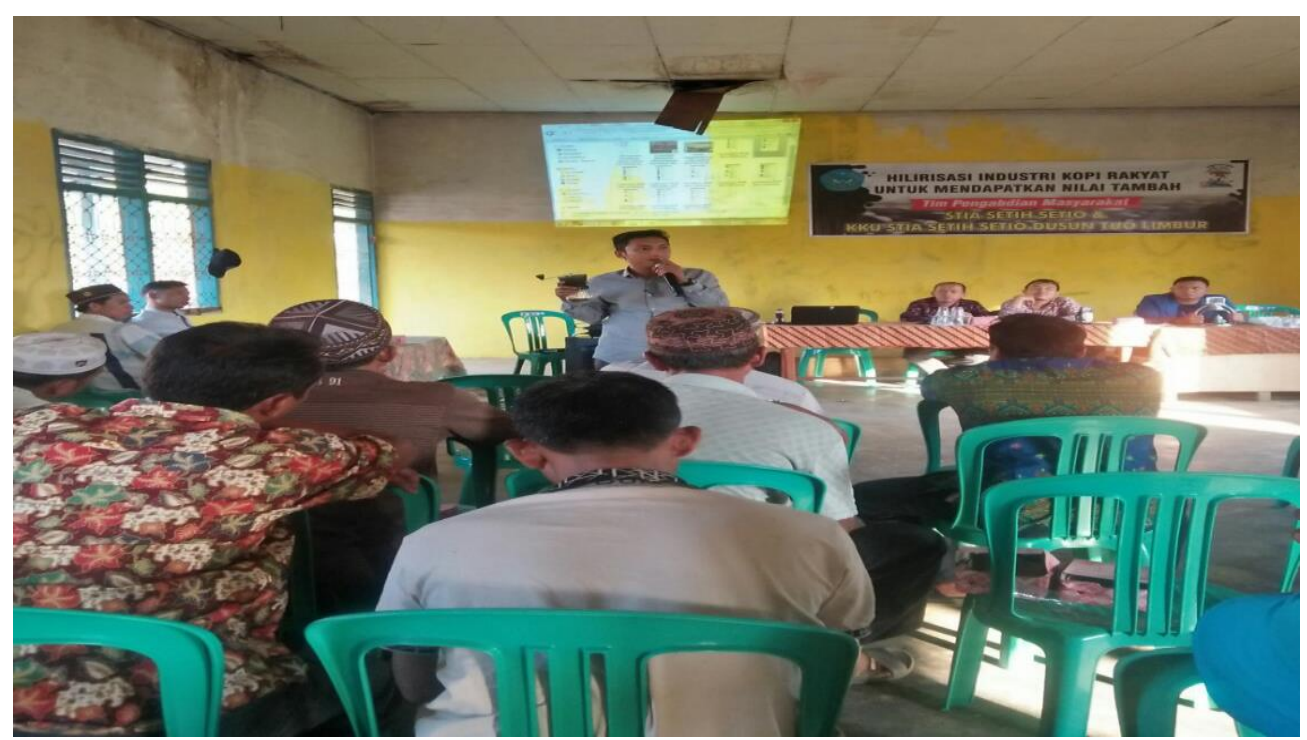

Gambar 2. Pemaparan budidaya, perawatan dan pengolahan kopi oleh narasumber

Terakhir pelaksanaan kegiatan ini diakhiri dengan praktik perkenalan peralatan penyajian kopi yang biasa dipakai di cafe yang ada di Muara Bungo dengan menggunakan grinder hario manual, mesin rok presso dan vietnam drip yang kemudian dicicipi oleh peserta pelatihan. Pada sesi terakhir ini pula dijembataninya petani kopi dengan satu-satunya micro roastery sekaligus pelaku usaha kopi yang ada di Kabupaten Bungo untuk menampung biji kopi dari petani kopi Dusun Tuo Limbur.

Permasalahan hilir dari industri kopi inilah yang banyak menjadi concern dari para petani yaitu ketika hasil produksi tanaman kopi ini ada dan melimpah kemana mereka menyalurkan biji kopi mentah tersebut? Karena pada saat ini mereka belum bisa mengolah menjadi produk setengah jadi dalam bentuk green bean maupun produk hilir berupa bubuk kopi yang berkualitas dan sesuai dengan permintaan pasar cafe yaitu bubuk kopi yang bisa diterima oleh berbagai macam alat penyeduhan kopi (brewing methods) yang dipakai di cafe. Dalam kegiatan ini alat yang digunakan untuk demo brewing methods adalah vietnam drip dan rok presso (espresso maker).

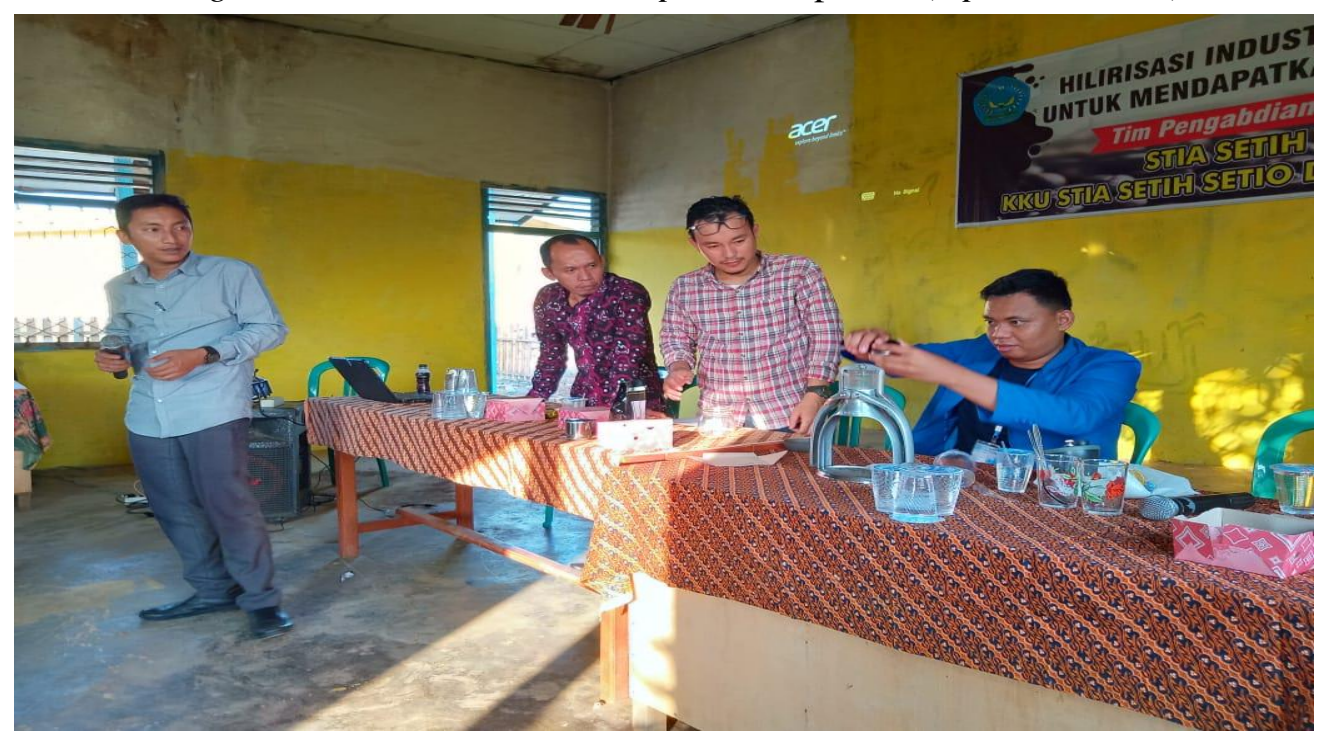

Gambar 3. Demo penyajian kopi espresso dengan manual brewing 


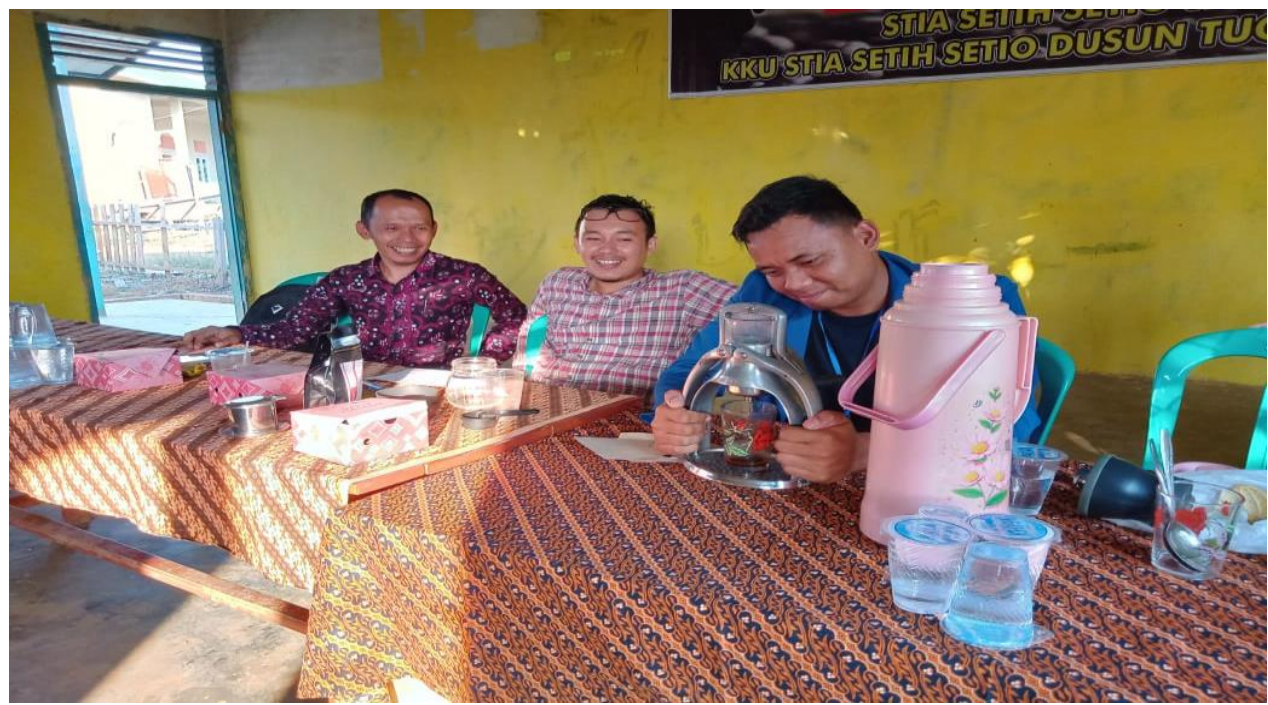

Gambar 4. Rok presso adalah alat yang digunakan dalam manual brewing

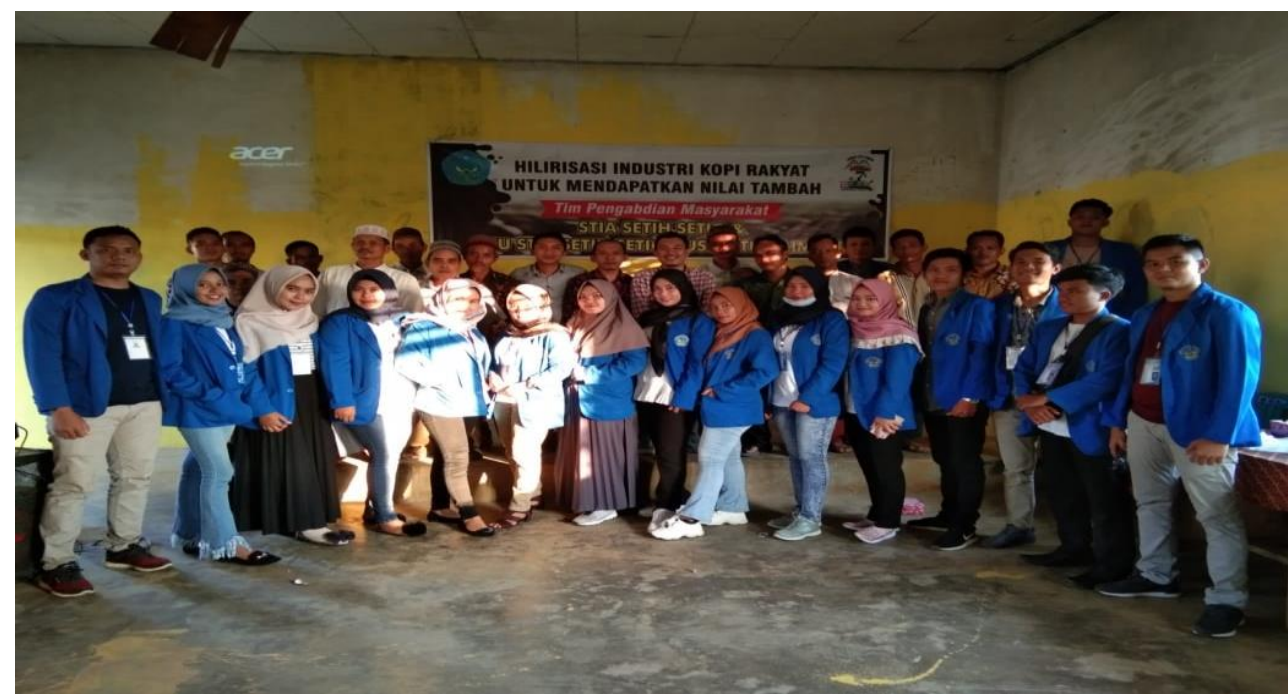

Gambar 5. Tim Pengabdian Hilirisasi Industri Kopi STIA Setih Setio

Luaran yang diharapkan dari kegiatan pengabdian kepada masyarakat tentang hilirisasi industri kopi ini selain adalah terjembataninya petani kopi di daerah potensial budidaya kopi ke hilir industri kopi yaitu micro roastery dan outlet-outlet penjualan kopi (cafe) yang menggunakan bubuk kopi untuk peralatan penyeduhan moderen di Kota Muara Bungo. Kafeinisme adalah satusatunya micro roastery yang dapat menampung biji kopi petani karena mempunyai peralatan pengolahan biji kopi pasca panen seperti mesin roaster (sangrai) dan grinder (penggiling) moderen.

Dampak dari program pengabdian masyarakat ini telah cukup dirasakan yaitu dengan terjembataninya petani kopi Dusun Tuo Limbur ke Coffee Roasters di Kota Muara Bungo yang juga memiliki cafe yaitu kafeinisme, beberapa cafe lainnya mengambil roasted beans dari kafeinisme untuk disajikan dalam berbagai metode brewing. Namun beberapa lainnya tidak diterima karena green beans yang diproduksi memiliki defect yang cukup masif sehingga kesulitan dalam proses roasting biji kopi yaitu tidak meratanya proses roasting.

Kopi madu libur adalah produk kopi specialty dari yang berasal dari Kecamatan limbur lubuk mengkuang yang menjadi lokasi pengabdian kepada masyarakat, yang diolah oleh coffee roaster bernama kevin selaku pemilik cafe kafeinisme yang menjadikan biji kopi tersebut selain untuk digunakan pada cafe yang dimilikinya, juga mengemas produk tersebut dalam bentuk roasted beans dan coffee powder yang telah di grinder. Dalam jangka panjang dan jika masih berlanjut diharapkan mencapai tujuan sosialnya yaitu kesejahteraan masyarakat dengan memproduksi langsung dari petani. 


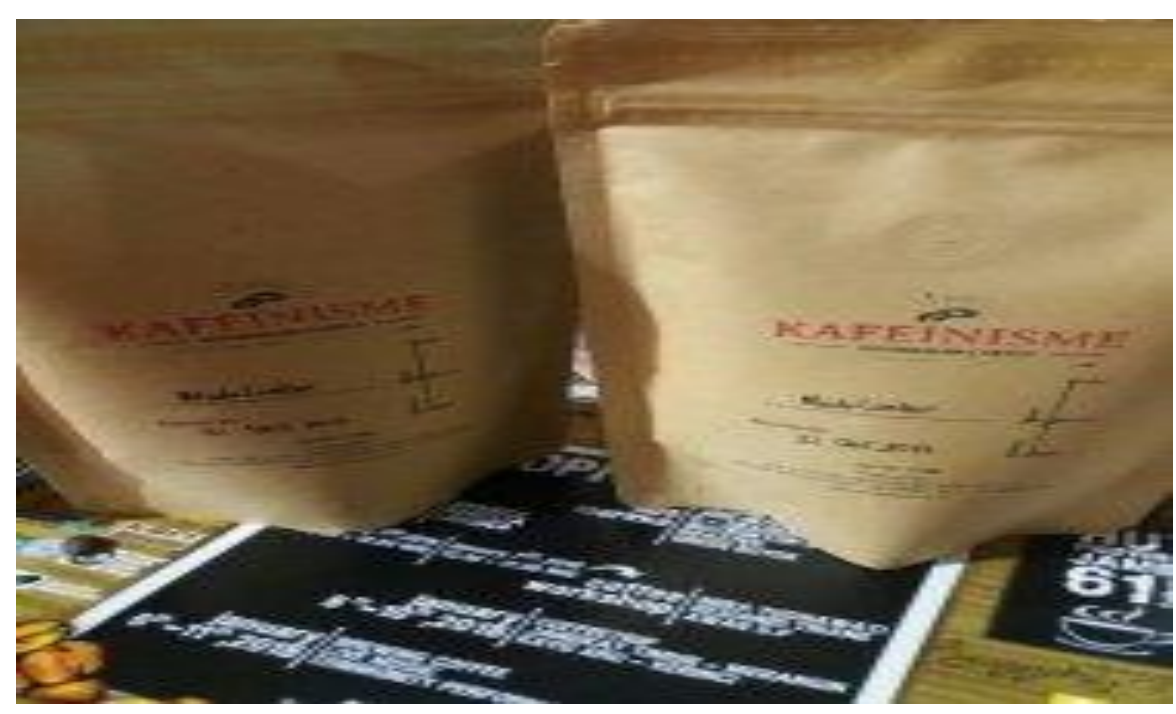

Gambar 6. Produk Kopi Kafeinisme Madu Limbur

\section{PENUTUP}

\section{Simpulan}

Permasalahan dalam hilirisasi industri kopi di Dusun Tuo Limbur ini adalah belum diolahnya biji kopi cherry oleh petani karena petani tidak memiliki pengetahuan dan peralatan yang memadai untuk pengolahan yang menghasilkan bubuk kopi berkualitas yang dipakai oleh pasar cafe. Selama pengabdian diketahui bahwa petani menjual hasil kopi cherry ke tengkulak tanpa proses sortasi dengan harga murah untuk didistribusikan ke ibukota Provinsi Jambi dan ke Provinsi Sumatera Barat. Dari kegiatan ini juga diketahui bahwa beberapa petani sudah terjembatani ke beberapa pasar cafe yang ada di Kota Muara Bungo, namun tidak semuanya terdistribusi secara maksimal karena masih banyak ditemukan defect pada green beans yang dikirim oleh petani.

\section{Saran}

Dari kegiatan/ program ini dapat disarankan untuk dilanjutkan secara berkelanjutan karena setelah terjembataninya petani kopi di Dusun Tuo Limbur, Limbur Lubuk Mengkuang ini, perlu adanya peningkatan terhadap kualitas biji kopi hijau yang dihasilkan oleh petani sehingga dalam jangka panjang petani daerah potensi kopi di Kabupaten Bungo secara umum dan khususnya Dusun Tuo Limbur, Limbur Lubuk Mengkuang dapat mehilirisasi industri kopi langsung dari hulu, dan kesejahteraan petani meningkat.

\section{DAFTAR PUSTAKA}

Ciptadi, W. dan Nasution, M. Z. (1985). Pengolahan Kopi. Agroindustri Press, Jurusan Teknologi Industri Pertanian IPB.

Kahpi, A (2017). Budidaya Dan Produksi Kopi Di Sulawesi Bagian Selatan Pada Abad Ke-19. Lensa Budaya Universitas Hasanuddin Makassar, Vol. 12, No. 1, 13-26

Novita, E. Et.,al. (2010). Peningkatan Mutu Biji Kopi Rakyat Dengan Pengolahan Semi Basah Berbasis Produksi Bersih, Jurnal Agroteknologi Universitas Jember, Vol. 4, No. 1, 76-90

Sulistyaningtyas, A. R. (2017). Pentingnya Pengolahan Basah (Wet Processing) Buah Kopi Robusta(Coffea Robusta Lindl.Ex.De.Will) Untuk Menurunkan Resiko Kecacatan BijiHijau Saat Coffee Grading, Prosiding Seminar Nasional LPPM UNIMUS Semarang 30 September 2017, 90-94

https://nasional.kompas.com/read/2017/10/02/09184261/diskusi-jokowi-dengan-pecinta-kopi-daritantangan-hingga-cita-cita?page $=$ all

https://economy.okezone.com/read/2018/08/08/320/1933644/ekspor-kopi-indonesia-450-000-tontahun-nilainya-rp1-68-triliun 